\title{
Blepharoptosis treatment as a complication due to botulinum toxin application
}

\author{
Ricardo Grillo ${ }^{1 *}$, Elda Ribeiro ${ }^{1}$, Adilson Chaves ${ }^{1}$ and Tarley EP de Barros ${ }^{2}$ \\ ${ }^{1}$ Dentist, Post-Graduate in oral and maxillofacial surgery, Lumière Odontologia e Estética Facial, Brazil \\ ${ }^{2}$ Dentist, PhD in Sciences, University of São Paulo, Brazil
}

\begin{abstract}
The application of botulinum toxin in the treatment for facial rejuvenation is a reality and is becoming increasingly accessible to everyone. Safe and fast procedure, with few complications. One of these complications is blepharoptosis, a ptosis of the upper eyelid. Although it does not pose great risks, the patient has an aesthetic complaint, in addition to loss of visual acuity. This article aims to list the treatment conditions available to treat blepharoptosis caused by application of botulinum toxin. There is still no antitoxin medication available. Alpha-adrenergic eye drops are a set with mechanical and thermal stimulation that are the most efficient and safe treatment for these cases.
\end{abstract}

\section{Introduction}

Complications resulting from the application of botulinum toxin are not frequent and, in most cases, resolve spontaneously in about 6 weeks. Among these complications, the one that causes the most complaints from patients is blepharoptosis. Blepharoptosis is due to the dispersion of the botulinum toxin through the fascia of the orbital septum to the levator muscle of the upper eyelid in the upper eyelid and is related to the application of botulinum toxin outside the safe area or to a marked dispersion of the toxin due to excessive manipulation of the region. Even with spontaneous resolution, patients report a lot of aesthetic and visual discomfort due to the decrease in the eyelid opening, making the waiting period for resolution extremely uncomfortable. There are not many articles in the literature that deal with the reversal of botulinum toxin in cases of complications and the present article intends to show which options are available in order to treat this complication and others that may arise, with the use of botulinum toxin.

\section{Material and methods}

An extensive literature review was carried out on the PubMed and BVS platforms in order to search for articles relating "botulinum toxin" + "reversion" in a total of 452 articles. All articles in Chinese and German were excluded, only articles in English, French, Italian and Portuguese were included. Articles that proved to be effective with clinical proof of results and articles that suggest some hypothesis of treatment were included, even without effective proof of the technique, so that future comparisons can be made. All articles with animal studies were excluded. The articles that obtained a positive response to the reversal but with delayed results were maintained even though the reversal may have occurred due to the time interval and loss of the effective action of the toxin.

\section{Discussion}

Blepharoptosis is an uncommon complication after application of botulinum toxin with an incidence of $5.4 \%$ in total. This incidence decreases close to $1 \%$ to $2 \%$ with more experienced professionals $[1,2]$, which serves as a warning for the importance of some steps such as the demarcation of the areas of safety and constant recycling of anatomical knowledge. Complications related to botulinum toxin resulting from dispersion have been related since 1987 and have been demonstrated by means of electromyography, where it has been demonstrated that this dispersion can occur from 3 to 13 days after application [3]. In addition to the dispersion to the region beyond where the effects are expected, there are two more theories that may explain some possible complication, retrograde axonal transport [4,5] and the fact that patients may have some neuromuscular disorder not yet diagnosed [6]. Despite disappearing between 4 and 6 weeks, patients complain a lot, not only about the aesthetic impact but also about the loss of visual acuity due to the reduction of the eyelid opening and many, even knowing the problem's self-resolution, seek the professional in order to that there is no other solution than waiting. None of these measures or medications should be used if patients do not report recent botulinum toxin application, and they should be referred to an ophthalmologist in order to assess the differential diagnosis, which may include myasthenia gravis, oculomotor nerve palsy, syndrome Horner's, Bell's palsy and others [7].

Medications: Anticholinesterase or alpha-adrenergic eye drops improve cholinergic transmission indirectly by inhibiting the destruction of acetylcholine, a fundamental chemical mediator in the transmission of nerve impulses, increasing or prolonging their effects. They cause Müller muscle contraction (upper tarsal muscles), which causes eyelid retraction of 1 to $2 \mathrm{~mm}$, improving the sensation

${ }^{\star}$ Correspondence to: Ricardo Grillo, Dentist, Post-Graduate in oral and maxillofacial surgery, Lumière Odontologia e Estética Facial, Rua das Figueiras, 1670 sala 5. Campestre, Santo André-SP, 09080-301, Brazil, E-mail: doutorgrillo@uol.com.br

Key words: botulinum toxins type A; blepharoptosis; pyridostigmine bromide

Received: March 05, 2020; Accepted: March 23, 2020; Published: March 27, 2020 
caused by eyelid ptosis $[1,2,8,9]$. Alpha-adrenergic eye drops work very well in cases of blepharoptosis caused by botulinum toxin, with few side effects 8 . They are not antitoxin substances, but their effects are related to the enhancement of neuromuscular transmission [10]. An overdose of anticholinesterases can cause hypersalivation, nausea, vomiting, abdominal cramps and diarrhoea, due to excessive muscarinic and nicotinic stimulation $[8,11]$. Be careful when indicating these medications in patients with closed-angle glaucoma and other eye changes. The patient's ophthalmologist should always be consulted [1]. Among these eye drops we can mention $0.2 \%$ brimonidine, $0.12 \%$ phenylephrine 2 , both with no clinical results [12] and $0.05 \%$ naphazoline $[7,12]$ that can be useful in the relief of blepharoptosis. These eye drops are used in the dose of 1 drop every 6 or 8 hours. Apraclonidine 0,5\% (Iopidine) in the dose of 1 to 2 drops, 3 times a day can be used $[1,2,7,13]$ and appears to be clinically more effective $[9,14]$. Between the moment of instillation of the drops and if the patient has no more complaints, the time interval can be from just 2 hours 7 to up to 4 weeks [14]. It can be used to reverse both botulinum toxin type A and type B [14]. Pyridostigmine is an anticholinergic medication, which also inhibits anticholinesterase [10], used to treat myasthenia gravis. The use of pyridostigmine should be reserved for refractory cases where alpha-adrenergic eye drops have not been successful in reversing blepharoptosis or for allergic patients [8,11]. Its use in patients with mechanical intestinal or urinary obstruction and asthmatic patients should be avoided. In some cases of dispersion causing serious side effects, in applications carried out on children, pyridostigmine can be used safely [10]. Used at a dose of $60 \mathrm{mg}$ orally when waking up one more dose every 6 or 8 hours, depending on the need [8,11]. The return of the eyelid to the anatomical position takes place about 2 hours after the first take. It can be used for up to 2 weeks without complications [11]. There are reports of the use of pyridostigmine to reverse blepharoptosis but without losing the effects of the toxin in the glabellar and frontal region [8]. Other alpha-adrenergic drugs such as aminopyridines and guanidine could also be used in cases of blepharoptosis since they act as antagonists of botulinum toxin, but there are no reports in the literature of these medications for this indication [8]. Researchers have not yet found a safe and effective drug in cases of reversion to botulinum toxin, but some studies have shown promise as in the case of covalent selenide inhibitors [15], inhibitors of the blocked voltage calcium channel [16], anti BoNT [17] and thioredoxin inhibitors reductase [18].

Physical: Physiotherapy and mechanical or electrical stimulation of the upper eyelid region help in the treatment of blepharoptosis. The use of the handle of an electric brush or a portable massager, a few minutes a day can accelerate the return of the muscles of the region to return to their normal contraction [1]. The author reports that this is a known technique and used in cases of blepharoptosis, however it has no scientific basis and is used only off-label. There are authors who report the use of plication with glue [19]. Plication is performed with a cyanoacrylate-based glue used to replace skin sutures in cases of small cutaneous injuries and children, as there is no need to use anesthesia. Plication with glue must be performed very carefully so that it does not overflow the eyelid region and end up adhering to other structures, especially the cornea. Only one article in the literature reports the use of this technique for reversing blepharoptosis and the authors were able to decrease the size of eyelid tissue from $24 \mathrm{~mm}$ to $13 \mathrm{~mm}$, improving the patient's vision and complaint. The authors themselves report that the best solution lies in waiting for the time to lose the effects of the toxin, but they used this technique due to the multiple complaints of the patient. In cases of eyebrow ptosis, polydioxanone threads can be used to pull the region and heal ptosis [20], but due to the upper eyelid anatomy, there is no report in the literature on blepharoptosis resolution using traction threads. Much is said about the use of other therapies to reverse botulinum toxin. Among these therapies we can mention the use of laser therapy [21], radiofrequency, microfocused ultrasound and intense pulsed light. Of all these therapies, no evidence of these was found in the reversal of botulinum toxin and the muscle paralysis caused, so much so that there are professionals who use one or more of these therapies and application of botulinum toxin in the same session, with the aim of facial rejuvenation, without loss of toxin effects $[22,23]$. What is believed is that radiofrequency, by stimulating paralyzed muscles, both thermally and mechanically, ends up decreasing the duration of the toxin, denaturing the protein, but it would not be as effective as reversal in cases of blepharoptosis. Some off-label treatments, such as the use of potent non-steroidal antiinflammatory drugs or injection of Dimethylethanolamine (DMAE), although they have a logic in reversing botulinum toxin, no article was found relating both to the reversion of botulinum toxin, both on the PubMed basis and on the BVS base.

\section{Conclusion}

Blepharoptosis is an uncommon complication and the most common way to deal with it is to wait for the botulinum toxin to lose its muscle paralysis effect on the muscles involved. In some cases where the aesthetic or visual complaint is accentuated, we can use some means to resolve the complaints, but there are still no means of reversing the toxin. Adrenergic eye drops are a good solution in cases of blepharoptosis and should be used as a first choice. Apraclonidine should be used to the detriment of pyridostigmine, as it should be used in more refractory cases and in allergic patients because it has more contraindications and side effects. Together, mechanical and thermal stimulation can be used in order to increase muscle metabolism at the site and try to eliminate botulinum toxin more quickly, but with non-immediate reversal effects. Greater care during the application of botulinum toxin and the study of anatomy are still the best way to prevent and reduce this complication, since there is still no effective antitoxin for cases of blepharoptosis.

\section{References}

1. King M (2016) Management of Ptosis. J Clin Aesthet Dermatol 9: E1-E4. [Crossref]

2. Wollina U, Konrad H (2005) Managing adverse events associated with botulinum toxin type A: a focus on cosmetic procedures. Am J Clin Dermatol 6:141-150. [Crossref]

3. Lange DJ, Brin MF, Warner CL, Fahn S, Lovelace RE (1987) Distant effects of local injection of botulinum toxin. Muscle Nerve 10: 552-555. [Crossref]

4. Restani L, Giribaldi F, Manich M, Bercsenyi K, Rossetto GMO, et al. (2012) Botulinum neurotoxins $\mathrm{A}$ and $\mathrm{E}$ undergo retrograde axonal transport in primary motor neurons. PLoS Pathog 8: e1003087. [Crossref]

5. Restani L, Novelli E, Bottari D, Leone P, Barone I et al. (2012) Botulinum neurotoxin A impairs neurotransmission following retrograde transynaptic transport. Traffic 13: 1083-1089. [Crossref]

6. Erbguth F, Claus D, Engelhardt A, Dressler D (1993) Systemic effect of local botulinum toxin injections unmasks subclinical Lambert-Eaton myasthenic syndrome. $J$ Neurol Neurosurg Psychiatry 56: 1235-1236. [Crossref]

7. Crist M (2011) Apraclonidine: A Real Eye Opener in Botox-Induced Ptosis. VA Boston Healthcare System - West Roxbury. American Academy Optometry.

8. Karami M, Taheri A, Mansoori P (2007) Treatment of botulinum toxin-induced eyelid ptosis with anticholinesterases. Dermatol Surg 33: 1392-1395. [Crossref]

9. Omoigui S, Irene S (2005) Treatment of ptosis as a complication of botulinum toxin injection. Pain Med 6: 149-151. [Crossref]

10. Boerner RM, Young DL, Gnagi SH, White DR, Halstead LA (2018) Pyridostigmine for the Reversal of Severe Adverse Reactions to Botulinum Toxin in Children. J Pediatr 194: 241-243. [Crossref] 
11. Young DL, Halstead LA (2014) Pyridostigmine for reversal of severe sequelae from botulinum toxin injection. $J$ Voice 28: 830-838. [Crossref]

12. Mendonça TB, Lummertz AP, Bocaccio FJ, Procianoy F (2017) Effect of LowConcentration, Nonmydriatic Selective Alpha-Adrenergic Agonist Eyedrops on Upper Eyelid Position. Dermatol Surg 43: 270-274. [Crossref]

13. Scheinfeld N (2005) The use of apraclonidine eyedrops to treat ptosis after the administration of botulinum toxin to the upper face. Dermatol Online J 11: 9. [Crossref]

14. Steinsapir KD, Groth MJ, Boxrud CA (2015) Persistence of Upper Blepharoptosis After Cosmetic Botulinum Toxin Type A. Dermatol Surg 41: 833-840. [Crossref]

15. Garland M, Babin BM, Miyashita SI, Loscher S, Shen Y, et al (2019) Covalent Modifiers of Botulinum Neurotoxin Counteract Toxin Persistence. ACS Chem Biol 14: 76-87. [Crossref]

16. Beske PH, Bradford AB, Hoffman KM, Mason SJ, McNutt PM (2018) In vitro and ex vivo screening of candidate therapeutics to restore neurotransmission in nerve terminals intoxicated by botulinum neurotoxin serotype A1. Toxicon 147: 47-53. [Crossref]

17. Lin L, Olson ME, Eubanks LM, Janda KD (2019) Strategies to Counteract Botulinum Neurotoxin A: Nature's Deadliest Biomolecule. Acc Chem Res 52: 2322-2331. [Crossref]
18. Pirazzini M, Tehran DA, Zanetti G, Megighian A, Scorzeto M et al. (2014) Thioredoxin and its reductase are present on synaptic vesicles, and their inhibition prevents the paralysis induced by botulinum neurotoxins. Cell Rep 8: 1870-1878. [Crossref]

19. Suhr MA, Günther M, Springer IN (2004) Ptosis relief after botox injection using dermabond. Plast Reconstr Surg 114: 262-263. [Crossref]

20. Kang KJ, Chai CY (2017) Immediate treatment of botulinum toxin type A-induced brow ptosis with polydioxanone cog thread insertion. J Cosmet Med 1: 46-51.

21. Semchyshyn NL, Kilmer SL (2005) Does laser inactivate botulinum toxin?. Dermatol Surg. 31: 399-404. [Crossref]

22. Cuerda-Galindo E, Palomar-Gallego MA, Linares-Garcíavaldecasas R (2015) Are combined same-day treatments the future for photorejuvenation? Review of the literature on combined treatments with lasers, intense pulsed light, radiofrequency, botulinum toxin, and fillers for rejuvenation. J Cosmet Laser Ther 17: 49-54. [Crossref]

23. Langelier N, Beleznay K, Woodward J (2016) Rejuvenation of the Upper Face and Periocular Region: Combining Neuromodulator, Facial Filler, Laser, Light, and Energy-Based Therapies for Optimal Results. Dermatol Surg 42: S77-S82. [Crossref]

Copyright: (C2020 Grillo R. This is an open-access article distributed under the terms of the Creative Commons Attribution License, which permits unrestricted use, distribution, and reproduction in any medium, provided the original author and source are credited. 